\title{
A QUALIDADE DA EDUCAÇÃO VERSUS RESULTADOS DAS AVALIAÇÕES EM LARGA ESCALA: UMA BREVE REFLEXÃO*
}

\author{
Lidia Maria Lopes Assis \\ Roberto Antonio Deitos \\ Margarete Chimiloski Dolla
}

\section{Introdução}

Neste capítulo, busca-se contextualizar as atuais políticas educacionais no estado do Paraná, referentes à avaliação em larga escala, trazendo para a reflexão o seu recrudescimento nos últimos anos, principalmente, no ano de 2019 , com a implantação de uma nova prova, denominada Prova Paraná. Objetivando demonstrar o alinhamento do estado do Paraná às políticas de resultados, em âmbito internacional e nacional, foi realizada a abordagem do PISA, avaliação internacional, e do SAEB, avaliação nacional. A revisão bibliográfica aponta que a estandardização dos resultados do desempenho dos discentes, principalmente representado pelo índice de Desenvolvimento da Educação Básica, IDEB, intenciona relacionar a qualidade educacional a esses resultados. Para confirmar os dados referentes à revisão bibliográfica, foi utilizada, como referência, pesquisa realizada por amostragem no município de Cascavel, em escolas públicas das redes municipais e estaduais, no ano de 2017. Os resultados da pesquisa evidenciam o acirramento da implementação de ações relativas à avaliação em larga escala e também da linearidade a uma política liberal de ênfase aos resultados.

No quadro das políticas educacionais vigentes, a avaliação externa vem se destacando como pilar das ações da Secretaria Estadual de Educação no Estado do Paraná, SEED. Mesmo já sendo desenvolvidas ações em nível nacional, a partir de 2019, a SEED intensificou a avaliação dos estudantes como proposta da atual gestão. Nessa perspectiva, foi implantada a Prova Paraná, objetivando, conforme a própria Secretária:

Oferecer subsídios para que os professores possam saber com mais precisão como seus alunos estão aprendendo e para que as escolas utilizem os resultados obtidos para ajudar os educadores. Com os resultados em mãos, as equipes diretivas e pedagógicas podem desenvolver ações direcionadas para melhorar a aprendizagem (PARANÁ, 2019, p/s).

Tal ação nos leva, como pesquisadores e profissionais atuantes nessa rede de ensino, a buscar elementos teóricos nos referenciais bibliográficos, bem como resultados de coleta de dados empíricos, que auxiliem a melhor compreender quais

${ }^{*}$ DOI - 10.29388/978-65-86678-87-1-0.f.114-128 
são, de fato, os objetivos de tal proposição. Isso porque tais fatores vêm na contramão de ações, como restrição de formação continuada aos professores, elevado número de alunos em sala de aula, ampliação da jornada de trabalho dos professores, com a supressão de horas-atividade, dentre outros fatores, que incidem diretamente sobre os resultados do trabalho efetivado nas escolas.

Para contextualizarmos a realidade, é necessário retomar alguns dados, considerando que, na história da avaliação externa, no Brasil, há uma trajetória que, invariavelmente, se apresenta com inspiração em modelos adotados por países desenvolvidos, fundamentando diferentes moldes, construindo paradigmas de avaliação e suscitando muitas discussões em torno da temática no país. Observa-se que, nas últimas décadas, a questão da avaliação adquiriu destaque no cenário da educação brasileira, apresentando-se nos discursos dos gestores como suposto importante instrumento para a melhoria da qualidade da educação.

De acordo com análise de Freitas (2005), desde 1930 até o final da década de 1980, diversas foram as razões para que o Estado empreendesse ações no sentido de "avaliar" a qualidade da educação no país. Em princípio, apresentou-se como necessidade de verificação de resultados, mediante os objetivos da educação nacional, com a intenção de aplicar a ciência para formação da consciência técnica, visando expandir e melhorar a educação. Na sequência, objetivava-se diagnosticar a realidade, com a finalidade de qualificar a expansão do atendimento escolar, sua administração, bem como o ensino. Mais adiante, tais práticas foram concebidas como relevantes para racionalizar, modernizar e beneficiar a ação educacional. Posteriormente, o que se observa é a intenção de valer-se de tais práticas, a fim de assegurar a regulação por parte do Estado, implantando a cultura de avaliação.

A partir de tal contexto, observa-se que a temática da avaliação em larga escala, ampliou-se no cenário da educação brasileira, fazendo parte dos debates presentes nos discursos e práticas, que, por vezes, a anunciam como mecanismo mensurador da qualidade e, em outros momentos, a reconhecem como mecanismo de controle social por parte do Estado. Assim, é objeto de análise e questionamentos quanto à sua finalidade nos diversos momentos, para saber se objetiva avaliar a instituição, o docente, o discente, o currículo, ou outros elementos do processo educacional.

A partir da década de 1990, as proposições de avaliação passam a ser implementadas de forma exacerbada e, como objeto de análise, nos limitamos à análise de um programa avaliativo nacional, o Sistema Nacional de Avaliação da Educação Básica, SAEB; um internacional, o Programa Internacional de Avaliação de Estudantes, PISA; e um terceiro, em nível estadual, a Prova Paraná.

\section{Alguns aspectos sobre a avaliação em larga escala no estado do Paraná}

A partir dos anos 1990, as políticas educacionais foram gestadas em conformidade com a perspectiva liberal e gerencial, não com o objetivo de garantir o 
aprendizado a todos que necessitassem da escolarização, mas sim, como resultado explícito de interesses econômicos externos e internos no país.

[...] a política educacional, particularmente a empreendida no Brasil, a partir da década de 1990, é a articulação e a consumação de forças econômicas e políticas hegemônicas que sustentam proposições que revelam forte tendência predominante de cunho liberal ou social liberal e definem significativamente os rumos das políticas públicas e da educação nacional. (DEITOS, 2010, p. 209).

$O$ atendimento às prescrições de agências reguladoras financeiras externas e também a implementação da política interna no país direcionaram o encaminhamento a partir de 1995, de várias políticas educacionais. Novas exigências se fizeram necessárias e a educação não poderia ficar apenas restrita aos espaços escolares, "[...] mas ampliada para os processos gerais da educação permanente e do desenvolvimento ao longo da vida, eleita como fator estratégico na construção dessa nova sociedade." (PACHECO, MORAES, EVANGELISTA, 2001, p. 186).

A reforma de ajuste estrutural trouxe a reforma do Estado, que, tendo redefinido suas atribuições, passou gradualmente a retirar investimentos dos serviços públicos, entre eles, a educação. Essa redução das despesas públicas configurou a necessidade de novos mecanismos de controle e responsabilização da lógica gerencialista.

Essa nova configuração das políticas educacionais induziu à criação de diferentes mecanismos de controle e responsabilização, fazendo com que as avaliações em larga escala passassem, então, a ter papel central.

A avaliação aparece assim como um pré-requisito para que seja possível a implementação desses mecanismos. Aliás, sem objetivos claros e previamente definidos não é possível criar indicadores e medir as performances dos sistemas numa época em que se caracteriza pela exigência de acompanhamento dos níveis de educação nacional e pela necessidade de manter e criar altos padrões de inovação científica e tecnológica para enfrentar a competitividade internacional (AFONSO, 2009, p. 49).

A avaliação externa começou a ser relevante para o Estado, pois os sistemas educacionais deveriam ser eficientes, capazes de produzir bons resultados, que pudessem ser verificados por meio das avaliações em larga escala. $O$ interesse pelos índices escolares passou a ser também dos empresários, que "[...] interessados na formação de competências e habilidades dos trabalhadores, necessárias para se extrair o optimum viabilizado pela produção flexível empunharam a bandeira da Qualidade Total na Educação". (SHIROMA, SCHNEIDER, 2012, p. 90).

Os governos adotaram, então, a avaliação externa dos sistemas de ensino, como forma de controle político do desenvolvimento social; os resultados dos exames 
figuraram de modo central para o planejamento educacional, visto serem concebidos como a melhor forma para constatar a eficácia e medir a qualidade.

Nessa perspectiva, compreende-se que:

A avaliação externa sobre os rendimentos dos alunos adquiriu centralidade justificada pelo fato de que os resultados medidos por testes padronizados nos moldes internacionais teriam reflexo direto no aumento da eficiência e eficácia dos sistemas de ensino, justificando maior controle por parte do Estado sobre os processos descentralizados de gestão do ensino e da "concessão" de autonomia às escolas (ZANARDINI, 2008, p. 110).

Nesse contexto, foi implantado o Sistema de Avaliação da Educação Básica SAEB, desenvolvido pelo Instituto Nacional de Estudos e Pesquisas Educacionais, INEP, desde o ano de 1988, sendo formado por um conjunto de avaliações externas em larga escala, o qual objetivava diagnosticar o sistema educacional brasileiro. Passou a ser aplicado em 1990, com uma amostra de escolas do Ensino Fundamental da rede pública urbana, expandindo-se, posteriormente, conforme critérios por edição, com periodicidade bianual.

Em 2005, o SAEB passou por uma reestruturação, ficando composto por duas avaliações: Avaliação Nacional da Educação Básica (ANEB) e Avaliação Nacional do Rendimento Escolar (ANRESC), conhecida como Prova Brasil. O SAEB avalia uma amostra da demanda estudantil no final do Ciclo I e II do Ensino Fundamental, além do 3o ano de Ensino Médio; já a Prova Brasil, é aplicada aos alunos dos 5o (quintos) e 9o (nonos) anos de todas as escolas públicas do país, que contemplem turmas com mais de vinte alunos. Nas duas situações, são avaliadas habilidades de alunos em Língua Portuguesa e Matemática (ZANARDINI, 2008).

O IDEB passou a ocupar espaço como um orientador de política pública, em prol da qualidade da educação, atuando como ferramenta para monitoramento das metas de qualidade do Plano de Desenvolvimento da Educação (PDE) para a educação básica, que estabelece como meta o IDEB do Brasil com média 6,0 (seis). Isso caracterizaria um sistema educacional que apresenta qualidade, em comparação aos países desenvolvidos, participantes da Organização para Cooperação e Desenvolvimento Econômico (OCDE, 2016).

Por meio de dados coletados pelo INEP, no que se refere à média nacional do IDEB, entre os anos de 2005 a 2017, além dos dados pertinentes ao estado do Paraná, foi possível observar que o referido estado apresentou um gradativo crescimento na média obtida, tanto no que se refere aos anos iniciais quanto nos anos finais do ensino fundamental; porém, tendo alcançado a meta, proposta para o ano de 2017, apenas nos anos iniciais do ensino fundamental. Já no ensino médio, não se configurou a realidade de média crescente, bem como o não alcance da meta estipulada para o ano de 2017.

Visando compreender o real motivo, ou objetivo, de obtenção de dados quantitativos, não se pode perder de vista que a avaliação precisa estar alinhada com 
o contexto educacional, considerando que possa atuar diretamente na promoção de mecanismos que promovam a qualidade almejada na educação. Dessa forma, a avaliação educacional, "[...] deve visar, sobretudo, objetivos de desenvolvimento pessoal e coletivo, ou seja, deve estar prioritariamente ao serviço de projetos de natureza mais emancipatória do que regulatória". AFONSO, (2008, p. 43).

Além da avaliação nacional por meio do SAEB, o INEP aplica, aos estudantes de 15 anos, a prova constante do Programa Internacional de Avaliação de Estudantes (PISA), com primeira edição em 2000, sendo que o Brasil é participante desde o início. É uma pesquisa de conhecimentos e habilidades de alunos na faixa dos 15 anos de idade, para alunos da $7 \underline{a}$ série em diante (atual 80 ano do Ensino Fundamental no Brasil), realizada nos países da Organização para Cooperação e Desenvolvimento Econômico (OCDE) e em países convidados. O sistema avalia as áreas de Leitura, Matemática e Ciências, a cada três anos.

Conforme dados da OCDE, do ano de 2016, a qualidade da educação no Brasil, comparada internacionalmente, é baixa, considerando que, em 2015, o país ficou na posição 59 a 66, dependendo da disciplina, de 73 regiões e países, no Programa Internacional de Avaliação de Alunos, PISA, com médias de notas em matemática (401 pontos), leitura (407 pontos) e ciências (377 pontos) abaixo das médias dos alunos da OCDE (de, respectivamente, 493, 493 e 490 pontos). Tais médias evidenciaram que não houve melhoras, comparando-se aos últimos anos. Em ciências, a média brasileira tem se mantido estável desde 2006; a de leitura, desde 2000; já em matemática, apresentou crescimento significativo de 21 pontos, desde 2003; no entanto, decresceu 11 pontos entre 2012 e 2015 (OCDE, 2016).

Tais resultados geram discursos falaciosos de que se investe muito em educação no país, com baixo retorno. Compara-se com países desenvolvidos no sentido de tentar evidenciar que os números são desproporcionais, porém, quando se considera a densidade demográfica do país e o investimento por aluno, tais afirmativas caem por terra. Retorna-se ao papel da escola como redentora, desconsiderando todo o contexto vivido pelo aluno, a ausência de investimento em políticas sociais, que poderiam amenizar realidades tão severas no que se refere à falta de acesso a bens essenciais. Em contrapartida, busca-se vilanizar os envolvidos no processo como incompetentes e apelar para a meritocracia em relação aos estudantes que supostamente não obtém êxito, que deixariam de aproveitar as oportunidades ofertadas.

Por meio de Relatório de atividades internacionais, o INEP afirma que são objetivos do PISA:

Mais do que avaliar o que os jovens aprendem dos conteúdos propostos nos currículos escolares, o Pisa visa saber o quanto e como eles estão preparados para a vida em sociedade no mundo contemporâneo. [...]. As questões abertas e de múltipla escolha, simulam situações da vida real e enfocam a capacidade analítica e de resolução de problemas dos alunos (BRASIL, 2007, p. 11). 
A interpretação dos resultados do Pisa ocorre por meio de vários níveis de desempenho estabelecidos, baseados na classificação da pontuação associada às habilidades que os estudantes devem dominar para alcançar a pontuação correspondente. Dois são objetivos da classificação: permitir a catalogação do desempenho dos estudantes e proceder a descrição do que são capazes de realizar. 0 programa não tem caráter de classificação individual, mas gera a pontuação dos estudantes, que é convertida na pontuação do país.

Compreendendo a relação entre as duas avaliações, sabe-se que o IDEB indica, por meio da pontuação alcançada, o cumprimento das metas estabelecidas no Termo de Adesão ao Compromisso Todos pela Educação, eixo do PDE que trata da Educação Básica. Assim, a lógica é a de que, para o Brasil chegar à média 6.0, em 2021, cada sistema deve evoluir conforme seu ponto de partida, visando reduzir a desigualdade educacional no país. O estabelecimento de tal meta significa levar em conta os anos iniciais do ensino fundamental, em termos da "qualidade" atingida, proficiência e rendimento (taxa de aprovação), de acordo com a média atual dos países desenvolvidos (países membros da OCDE). Dessa forma, a comparação internacional foi estabelecida em vista de uma técnica de compatibilização entre a distribuição das proficiências, observadas no PISA e no SAEB, portanto, há uma estreita relação entre as duas formas de avaliação.

Em nível estadual, a partir do ano de 2019, passou-se a aplicar a Prova Paraná, que foi desenvolvida pela Secretaria de Educação, em parceria com o Centro de Políticas Públicas e Avaliação da Educação, da Universidade Federal de Juiz de Fora, bem como da empresa Mira Educação, com periodicidade de aplicação bimestral entre os alunos da rede estadual. De acordo com o secretário de Educação, Renato Feder, "[...] o objetivo é ajudar o professor a acompanhar o aprendizado dos alunos individualmente" (FEDER, 2019, p. 01).

A Prova contemplou 20 questões objetivas de Matemática e 20 de Língua Portuguesa; na primeira edição, no mês de março de 2019, foram aplicadas a alunos do 5ㅇ ano do Ensino Fundamental das redes municipais, do 6을 ao 9을 anos do Ensino Fundamental e do 1을 a 3 o anos do Ensino Médio, da rede estadual, num total de 434.886 alunos da rede estadual e 98.926 das redes municipais. Na segunda edição, ocorrida no mês de junho, além dos alunos que participaram da primeira etapa, também fizeram a prova estudantes dos 2으, 7으 e 8o anos do Ensino Fundamental e da 2a série do Ensino Médio.

Os resultados da primeira edição da Prova Paraná, em Língua Portuguesa e Matemática, apontam para problemas maiores de aprendizado no Ensino Médio. Os números mostram que, na disciplina de Matemática, os alunos apresentaram menor índice de acertos. No geral, a 1ạ e a 3 a séries do Ensino Médio tiveram os piores resultados: a média de acerto dos alunos foi de $28,55 \%$ e $29,62 \%$, respectivamente.

Os resultados, referentes ao SAEB 2017, apontam que, mesmo que o Paraná esteja melhor em relação a outros estados, ainda é preciso avançar. Na comparação entre o ensino fundamental e médio, o último aparece com os piores resultados na avaliação do MEC, assim como na Prova Paraná. 
O Secretário de Educação, Renato Feder, afirma ter ficado satisfeito com a aplicação do exame, em termos de adesão, porém, demonstra insatisfação com o número de acertos.

Fiquei feliz, foi excelente em termos de adesão, comprometimento. Jogou uma energia positiva na rede. Mas o resultado foi ruim, principalmente em matemática", avalia ele. Complementa ainda que o mau resultado e já era esperado, em função do resultado do IDEB, divulgado pelo MEC no ano passado. Dessa forma "está coerente com o que a gente viu no IDEB. Não tem como num período tão curto ter uma melhora significativa. Especialmente no Ensino Médio a gente sabia que o resultado não seria maravilhoso. $O$ que a gente busca é uma evolução (FEDER, 2019, p. 01.)

Em publicação, o representante do Sindicato dos Professores do Paraná se manifesta, reportando-se à Prova Paraná como:

[...] um projeto grandioso e ambicioso, e, mesmo que a SEED não admita que esta tenha como objetivo criar padrões de comparação, evidentemente que isso acabará acontecendo, até mesmo porque esta é uma finalidade intrínseca a este tipo de avaliação estandardizada, gerando ranqueamento entre as diferentes redes e escolas e, como consequência, teremos um modelo vertical de responsabilização, que em um futuro próximo gerará algum sistema de bonificação. (APP SINDICATO, 2019, s/p)

Complementa, ainda, afirmando:

Nossa defesa sempre é por um sistema de avaliação sistêmico, compreendendo os resultados escolares como consequência de uma série de fatores extra e intraescolares e que intervêm no processo educativo em que se considera a aprendizagem e o consequente rendimento escolar como produto, não só do conhecimento em si, mas também das práticas sociais. Nesse sentindo, envolve um conjunto grande de variáveis que precisam ser ponderadas [...] e que subjazem o processo avaliativo e nos quais se balizam o processo de ensino-aprendizagem. (APP SINDICATO. 2019, $s / p)$.

São aspectos que precisam ser ponderados no sentido de se buscar o desenvolvimento de um trabalho voltado para a melhoria do processo de ensino e aprendizagem, garantindo o direito à educação nos aspectos de acesso, permanência e êxito. E, portanto, ainda que muitos rumores de descontentamento com a proposta de avaliação tenham surgido na informalidade, houve adesão às avaliações também com a expectativa da contrapartida da mantenedora. 
A partir da primeira Prova Paraná, uma das ações desenvolvidas pela SEED se trata da Tutoria Pedagógica. Assim, técnicos dos Núcleos Regionais de Educação (NREs) passaram a visitar semanalmente as escolas, com objetivo de:

[...] auxiliar os gestores a implementar ações e estratégias visando contribuir com o processo de ensino e aprendizagem, combater o abandono escolar e reduzir os índices de reprovação na rede estadual por meio do fortalecimento da gestão escolar e do trabalho pedagógico (PARANÁ, 2019, p. 1).

Foi disponibilizada, aos professores, a prova comentada, apresentando a resolução e a descrição de cada questão, que pôde ser utilizada como material de apoio para o professor trabalhar em sala de aula. Também, foi elaborada pela mantenedora uma lista de exercícios com sugestões de atividades, com intuito de ajudar na abordagem dos conteúdos.

Para o segundo semestre, foi proposto o Projeto Mais aprendizagem, que, de acordo com a SEED, apresenta três diferenciais:

[...] acolhe estudantes com dificuldades em disciplinas variadas e recebe alunos de todas as séries do Ensino Fundamental - Anos Finais e do Ensino Médio. Além disso, os estudantes são organizados em três níveis, o que possibilita atender melhor as necessidades pedagógicas de cada grupo de alunos (PARANÁ, 2019, p. 1).

Tal proposição foi feita, porém, com possibilidade de atendimento bastante restrita, já começando com a carga horária do docente para esse trabalho, o qual poderia ser habilitado em qualquer licenciatura, desde que demonstrasse interesse e obedecesse aos critérios estabelecidos quanto à carga horária abdicada em turmas na escola.

Ao final do ano letivo, foi proposta uma ação denominada "Se liga, é tempo de aprender mais." A proposição contemplava a elaboração de um plano de recuperação de estudos para ser desenvolvido nos últimos 15 (quinze) dias letivos. No Plano de Estudos, deveriam ser retomados conteúdos essenciais para a série cursada e, ao docente, caberia abordá-los com metodologias diferenciadas da primeira abordagem. O Plano de Recuperação deveria ser proposto a todos alunos com nota inferior à média 6,0, portanto, com risco de retenção no ano escolar cursado. Tal proposta gerou uma série de polêmicas, em razão de se contrapor à concepção de avaliação, que trata da aprendizagem como processo, assim como a avaliação, que deve ser diagnóstica, contínua e processual.

Em relação à ação: "Se liga é tempo de aprender mais", foi proposto, também, aos docentes, que notas do 1 으 ou 2 을 trimestre, que estivessem abaixo da média 6,0 (seis), poderiam/deveriam ser substituídas pelas notas recuperadas, de forma a possibilitar a aprovação do estudante. Foi solicitado o encaminhamento ao NRE das ações e cronograma de como a escola implementaria o referido programa, no qual, 
entre as sugestões de ações, constavam: realização de monitorias no contra turno ou mesmo em sala de aula, reorganização de turmas e também de horários de aulas.

Enfim, tais foram as proposições da mantenedora para melhoria dos resultados dos índices escolares, sendo que alguns demonstraram ser inviáveis, pois mudanças de horários, durante o ano letivo, são muito difíceis de ser realizadas, em razão de, muitas vezes, o docente trabalhar em mais de uma escola; ademais, a proposta de separar alunos por níveis de aprendizado vai contra a proposta da escola democrática e inclusiva; quanto à sugestão de monitoria, para realizá-la, é necessária a organização logística para atendimento e acolhimento do estudante fora de seu horário escolar.

As ações propostas demonstram relativo desconhecimento da realidade da grande maioria das escolas paranaenses e reforça a ideia de que essas ações foram planejadas, tendo em vista o aumento quantitativo da aprovação dos estudantes em todo estado do Paraná, números que refletirão diretamente nos resultados do IDEB.

As ações implementadas, referentes à avaliação em larga escala, realizadas no Paraná, no ano 2019, confirmam pesquisa efetivada por amostragem, no ano de 2017, nas escolas da educação básica do município de Cascavel, no estado do Paraná. Nessa ocasião, foram analisadas 8 (oito) escolas, da rede municipal e estadual, com o objetivo de verificar, na perspectiva dos sujeitos docentes, se os indicadores educacionais, além do diagnóstico quantitativo, induzem à adoção de políticas para efetiva melhoria da educação básica nas escolas das redes públicas municipais e estaduais, na cidade de Cascavel, no Paraná, no período de 2010 a 2016 . O estudo foi efetuado pela coleta de dados por meio de questionário ${ }^{1}$; buscou analisar, a partir dos sujeitos docentes, se a qualidade da educação básica pública, mensurada pelo IDEB, refletia-se nas condições de trabalho dos professores e na qualidade do atendimento ao estudante.

Dessa forma, foram analisadas três dimensões básicas, referentes à efetivação da qualidade escolar: os sujeitos docentes e a qualidade da educação básica, as condições estruturais e pedagógicas do ambiente para qualidade da educação básica e o desempenho discente e a qualidade da educação básica. Quanto à primeira dimensão analisada, foram levantados dados referentes ao tempo de atuação na escola, sendo que responderam à pesquisa, formação acadêmica e rotatividade a cada término de ano letivo e até mesmo durante o ano letivo. Quanto ao tempo de trabalho nas escolas, independentemente do vínculo administrativo da mantenedora ser municipal ou estadual, verificamos que a maioria dos professores participantes da pesquisa trabalham com tempo igual ou inferior a 5 (cinco) anos. $O$ pouco tempo de serviço dos professores, apontado nesta pesquisa, coincide com a análise da OCDE, ao

\footnotetext{
${ }^{1} \mathrm{O}$ questionário foi realizado como levantamento de dados para pesquisa de Dissertação de Mestrado em Educação, da Universidade Estadual do Oeste do Paraná, pela autora Lidia Maria Lopes Assis orientada pelo professor doutor Roberto Antonio Deitos. A pesquisa de campo foi realizada em oito escolas do município de Cascavel, Paraná, no ano de 2017 e atendeu os princípios do Comitê de Ética e Pesquisa com Seres Humanos da UNIOESTE, foi aprovada conforme Parecer de número: 1.872 .667 , datado de 15/12/2016. Responderam a pesquisa 119 professores que trabalham diretamente nos dois ciclos da educação básica, ensino fundamental e ensino médio, atendidos majoritariamente e respectivamente pela rede municipal (1으 e 5음 anos) e rede estadual (6으 e 9응 anos e ensino médio) do município de Cascavel.
} 
constatar que, ao se relacionar à faixa etária, o Brasil tem os professores mais jovens dos 75 países em que foi aplicada a prova PISA, em 2015:

O grupo de docentes da educação básica no Brasil se destaca como um dos mais jovens em média entre os países pesquisados. Apenas $15 \%$ dos professores brasileiros dos anos iniciais possui mais de 50 anos. [...] Somente em dois países, no Brasil (52\%) e na China (66\%), mais da metade dos professores tem menos de 40 anos de idade (OCDE, 2015, p. 10).

Uma das possibilidades de interpretação para o dado apontado pela OCDE pode ser a não escolha da docência como profissão, abandono da docência para escolha de profissões mais atraentes, quanto às condições de trabalho e salário, e até mesmo a busca pelo professor de uma escola com melhor ambiente de trabalho. Em relação à rotatividade do professor, em escolas da rede estadual, situadas, principalmente, na periferia do município, a rotatividade era muito superior às das escolas localizadas na área central da cidade.

A rotatividade dos professores é prejudicial para a identidade institucional da escola, formada pelo grupo de professores que nela trabalhavam. Essa identidade institucional, segundo Silva Junior (2012), se perdeu ao longo da história de nossas escolas públicas, pois "[...] seus professores, obrigados pelas circunstâncias, subdividem sua jornada e multiplicam seus locais de trabalho" (SILVA JÚNIOR, 2012, p. 74).

Às escolas, resta, nesse contexto, "contar com apenas fragmentos de trabalho e fragmentos de pessoas. Fragmentos dinâmicos que, de certa maneira, constituem aquilo que a ideia de pósmodernidade sugere a todos" (SILVA JÚNIOR, 2012, p. 74).

Em relação à formação acadêmica do docente, especialização, mestrado ou doutorado, os docentes que responderam disseram ter realizado mais atividades de especialização e formação acadêmica, além de haver mais professores com mestrado e doutorado, que apresentam menor rotatividade durante o ano letivo; também, é onde há maior número de professores que estavam trabalhando há mais de cinco anos na mesma escola. Essas questões, relacionadas ao sujeito docente, são fundamentais para efetivação da qualidade escolar, defendida por Libâneo (2001):

Também precisamos imensamente de professores bem preparados, eticamente comprometidos, que tenham um envolvimento no projeto da escola e na execução e avaliação desse projeto. Isso depende, em boa parte, de uma recuperação da significação social da atividade do professor, ou seja, da identidade profissional do professor. O nosso dia de trabalho como professores será um sofrimento, um tormento, uma frustração se nós perdermos, para a sociedade e para nós mesmos, o significado do nosso trabalho, 
nosso papel social, nossa identidade. Se o professor perder o significado do seu trabalho, ele perde a identidade da sua profissão e, perdendo isso, ele perde um pedaço importante da sua existência, que é o trabalho cotidiano e, mais que isso, a sua dignidade de pessoa (LIBÂNEO, 2001, p. 25).

Entretanto, no estado do Paraná, as atuais políticas educacionais demonstram agir na contramão do processo de valorização do docente, pois o último concurso público para professores da rede estadual foi realizado no ano de 2015. Reiteramos, também, o já citado quanto à redução do tempo de hora-atividade do professor, o elevado número de alunos por sala de aula e até mesmo a situação da reforma da previdência dos servidores da rede estadual, ocorrida sem que a categoria dos docentes fosse ouvida, o que gerou instabilidade à carreira do profissional e, certamente, incidiu sobre a qualidade do trabalho.

A segunda dimensão, trazida para análise, referia-se à estrutura física e ambiente escolar das escolas, objetivando verificar como os professores estavam percebendo seu espaço de trabalho; ficou evidente a insatisfação dos docentes quanto à estrutura física da escola onde trabalhavam, pois apenas $27 \%$ dos docentes consideraram que a estrutura física estava apropriada aos fins educacionais; $40 \%$ dos docentes consideraram que seriam necessárias reformas ou manutenção em caráter de urgência; e 33\% consideraram a escola com a estrutura física insuficiente e inapropriada para atendimento aos estudantes. Quanto à estrutura física, o estudo procurou verificar espaços pedagógicos, a exemplo da biblioteca, sala de informática, laboratório de ciências naturais, além da disponibilidade de materiais e equipamentos para uso pedagógico. Os resultados da pesquisa demonstraram a fragilidade das bibliotecas na maioria das escolas, pois apenas $26 \%$ dos docentes consideraram adequada para os fins a que se destina; o laboratório de informática, tendo em vista que $53 \%$ dos professores consideraram como um espaço apropriado, uma vez que, em muitos casos, o docente, para agilizar seu trabalho, obriga-se a fazer uso de equipamentos pessoais, como notebook, celular e até mesmo conexão à internet particular.

Quanto ao laboratório de ciências naturais (física, química e biologia), a maioria dos professores responderam não haver esse espaço pedagógico; onde há, é considerado impróprio para utilização. Diante disso, apenas para a minoria dos docentes, o laboratório de ciências se configura como espaço de estudo, levando-nos a inferir que esse é um local que vem sendo desconsiderado e precarizado.

Em relação aos materiais didáticos e equipamentos pedagógicos (multimídia, aparelhos de som, livros didáticos, fotocópias de atividades, materiais para aulas de educação física e artes), a minoria, representados por (trinta e três por cento) 33\% dos professores, os consideraram suficientes e em boas condições de uso. Os materiais foram evidenciados como insuficientes para $57 \%$ (cinquenta e sete por cento) e inadequados para 6\% (seis por cento), sendo que alguns professores relataram que não havia materiais, efetivando-se necessário trazê-los de casa. 
Constatamos que as condições estruturais mostravam-se fragilizadas, carentes de materiais didáticos e equipamentos tecnológicos, pertinentes para efetivação do aprendizado, refletindo-se diretamente na qualidade do trabalho escolar. Como para todos os espaços pedagógicos há uma normatização legal, verificamos, a partir das respostas dos docentes, que não estão implementadas na cidade de Cascavel, em grande parte das escolas.

Consideramos que a edificação escolar faz parte da história do estudante e é o local que, mesmo após concluídos os estudos, a pessoa sente orgulho por ter frequentado: "Os seus egressos retornam e querem ver suas antigas salas de aula; eles querem ver as estantes de troféus e as velhas fotografias, ouvir os ecos no ginásio e caminhar nos pátios de recreio" (RAVITCH, 2011, p. 253).

Dessa forma, nossa concepção é de que a escola se constitui como patrimônio histórico e cultural da comunidade a qual pertence, merecendo ter um tratamento cuidadoso pela própria comunidade escolar, mas, sobretudo, por políticas da mantenedora, para que as instalações estejam sempre em bom estado de conservação. Isso, visando acolher e incentivar a permanência de estudantes, em que a ausência de equipamentos e materiais didáticos não seja uma restrição aos professores para a efetivação do processo de ensino e aprendizagem.

\section{Considerações finais}

A avaliação em larga escala, institucionalizada no Brasil desde os anos de 1990, vem sendo revigorada, no estado do Paraná, com a implementação verticalizada de algumas estratégias que objetivam resultados quantitativos. A proposição e encaminhamentos, referentes à implantação e aplicação da Prova Paraná, no estado do Paraná, demonstraram ser uma forma de preparar estudantes da educação básica para a realização da Prova SAEB, cuja aplicação efetivou-se no mês de novembro de 2019. Consideramos também que a proposição da ação, realizada ao término do ano letivo, pela Secretaria Estadual de Educação: Se liga, é tempo de aprender mais!, pode também influenciar os resultados de aprovação de estudantes e, consequentemente, os resultados da nota do IDEB. Os dados trazidos para análise da pesquisa por amostragem, realizada no ano de 2017, em escolas das redes públicas municipais e estaduais, em Cascavel, Paraná, apontam a falta de incentivo na formação do docente e valorização salarial, fragilidade nas estruturas físicas de grande parte das escolas, com espaços pedagógicos precários; por outro lado, o discurso de modernidade tecnológica tem sido o mote da atual gestão.

Compreendemos que as políticas de avaliação necessariamente devem estar articuladas às políticas de ensino, de formação de professores, de apoio didáticopedagógico, gestão de escolas, dentre outros que contemplem o que é propalado nos discursos referentes à educação, que, geralmente, são carros chefes nas campanhas políticas. Assegurar a articulação, continuidade e abertura à participação dos envolvidos no processo educativo são aspectos essenciais para a efetivação de 
políticas educacionais coerentes, com possibilidade de avanços em direção a uma educação de qualidade.

\section{Referências}

AFONSO, Almerindo Janela. Avaliação Educacional: regulação e emancipação. Para uma sociologia das políticas avaliativas contemporâneas. 4ạ edição. São Paulo: Cortez, 2009.

AFONSO, Almerindo Janela. Avaliar a escola e a gestão escolar: elementos para uma reflexão crítica. In: ESTEBAN, Maria Teresa. Escola, currículo e avaliação. $3^{\circ} \mathrm{Ed}$. São Paulo: Cortez, 2008.

ALAVARSE, Ocimar Munhoz; MACHADO, Cristiane. Qualidade das Escolas: tensões e potencialidades das avaliações externas. Educação e Sociedade. Porto Alegre, v. 39, n. 2, p. 413-436. http://www.scielo.br/pdf/edreal/v39n2/v39n2a05.pdf. Acesso em 13 nov. 2020.

ALICIO, Eleucineia. POLI, Ednéia Consolin. Um olhar sobre a avaliação em larga escala: ações a partir do estudo do IDEB 2007/2011. In: Os desafios da escola púbica paranaense na perspectiva do professor PDE. Produções Didático-Pedagógicas Versão Online ISBN 978-85-8015-079-7. Secretaria Estadual de Educação do Paraná, Cadernos PDE. Volume II, Curitiba. 2014.

APPSINDICATO. Prova Paraná: o que você precisa saber sobre essa avaliação diagnóstica. Disponível em: https://appsindicato.org.br/prova-parana-o-que-voceprecisa-saber-sobre-essaavaliacao-diagnostica. publicado em 13 de março de 2019. Acesso: 02 jan. 2020.

APPSINDICATO. Manifesto por uma educação humanizadora contra o projeto do governo do Paraná de mercantilização. Conselho Estadual da APP-Sindicato. http://appsindicato.org.br/manifesto-por-uma-educacao-humanizadora-contraamercantilizacao-da-escola-publica. Curitiba, 25 de Maio de 2019. Acesso: 02 jan. 2020.

BRASIL. Panorama da Educação. Destaques do Education of a Glance 2015. INEP. Instituto Nacional de Pesquisas e Estudos Educacionais. Brasilia. DF. http://download.inep.gov.br/acoes_internacionais/eag/documentos/2015/dest aques_do_panorama_da_educacao_2015_eag_final.pdf. Acesso em: 11 jan. 2020.

BRASIL. Panorama da Educação. Destaques do Education of a Glance 2015. INEP. Instituto Nacional de Pesquisas e Estudos Educacionais. Brasilia. DF. http://download.inep.gov.br/acoes_internacionais/eag/documentos/2015/dest aques_do_panorama_da_educacao_2015_eag_final.pdf. Acesso em 11 jan. 2020. BRASIL. IDEB 2005 e projeções para o Brasil. Brasília: MEC. INEP, 2007a. Disponível em: www.ideb.inep.gov/site. Acesso em 20 dez. 2019. 
BRASIL. Nota metodológica sobre a compatibilização de desempenhos do PISA com a escala do SAEB. MEC. INEP. Brasília. Disponível em:

http://download.inep.gov.br/educacao_basica/portal_ideb/metodologias/Nota_ Tecnica_n3_compatibilizacao_PISA_SAEB.pdf. Acesso em: 31 dez. 2019.

DEITOS. Roberto A. Políticas Públicas e Educação: Aspectos Teórico-ideológicos e socioeconômicos. Acta Scientiarum Education. Maringá, 2010. p. 209-219.

FONTES, Giulia e SCORTECCI, Catarina. Prova Paraná: veja onde estão os problemas e os melhores desempenhos dos alunos. Entrevista Secretário de educação e Esporte do Paraná - Renato Feder. Jornal Gazeta do Povo. Curitiba, 17 de abril de 2019. Disponível em: https://www.gazetadopovo.com.br/parana/provaparana-resultadosmarco-2019.

FREITAS, D. N. T. A avaliação da educação básica no Brasil: dimensão normativa, pedagógica e educativa In: REUNIÃO ANUAL DA ANPED, 28., 2005, Caxambu. Anais... Caxambu, MG: ANPED, 2005.

FEDER, Renato. "Prova Paraná: veja onde estão os problemas e os melhores desempenhos dos alunos. Entrevista Secretário de educação e Esporte do Paraná Renato Feder por Giulia Fontes, com colaboração de Catarina Scortecci [17/04/2019] [14:47]. Disponível em: https://www.gazetadopovo.com.br/parana/prova-paranaresultados-marco2019.

LIBÂNEO, José Carlos. Pedagogia e Pedagogos: inquietações e buscas. Educar, n. 17, p. 153-176. Editora da UFPR. Curitiba, 2001.

LOPES ASSIS. Lidia Maria. Os sujeitos docentes e a qualidade da Educação básica: indicadores de rendimento escolar da rede pública municipal e estadual de Cascavel no Paraná. Lidia Maria Lopes Assis. Dissertação (Mestrado em Educação).

Universidade Estadual do Oeste do Paraná, Campus de Cascavel, Centro de Educação, Comunicação e Artes. Programa de Pós-Graduação. 2018.

MELLO, Guiomar Namo de. Escolas eficazes: um tema revisitado. (Série Atualidades pedagógicas; n. 6). BBE, v. 39, n. 1, Brasília: MEC/SEC, 1994.

PACHECO, José, MORAES, M. Célia, EVANGELISTA, Olinda, (2001). Políticas educacionais nos anos 90: a formação de professores no Brasil e em Portugal. Educar em Revista, № 18, p. 185-200.

PARANÁ. Prova Paraná: a partir dos resultados, educação desenvolve ações para melhorar aprendizagem. Portal dia a dia Educação. SEED. Publicado em 17/04/2019. Disponível em: http://www.educacao.pr.gov.br/modules/noticias/article.php? storyid=8111\&tit=Prova-Parana-apartir-dos-resultados-Educacao-desenvolve-acoespara-melhorar-aprendizagem.

RAVITCH, Diane. Vida e morte do grande sistema escolar americano: como os testes padronizados e o modelo de mercado ameaçam a educação. Tradução de Marcelo Duarte. Porto Alegre: Sulina, 2011. 
SEED/PR. Ofício Circular no. 126/2019 - DEDUC/SEED Assunto: Ações pedagógicas do "Se liga! É tempo de aprender mais! Curitiba, 24 de outubro de 2019.

SEED/PR. Tutoria Pedagógica: novo projeto ajuda escolas estaduais no desenvolvimento da gestão escolar e ações pedagógicas. Publicado em 15/04/2019.

SEED/PR. Programa Mais Aprendizagem. Mais de 750 escolas recebem programa voltado a estudantes com dificuldade de aprendizagem. Publicado em 20/06/2019

SILVA JÚNIOR. Celestino Alves da. Avaliação de larga escala e organização do trabalho na escola. In: WERLE, Flávia Obino Corrêa. Avaliação em larga escala: questões polêmicas/ (organizadora). Brasília: Liber Livro, 2012.

SHIROMA, Eneida Oto; SCHNEIDER, Mara Cristina. Avaliação de desempenho docente: contradições da política-para-poucos-na era do para-todos. Interação (UFG. Impresso), v. 38, p. 89-107, Goiás, 2013.

ZANARDINI, João Batista. Ontologia e Avaliação da Educação Básica no Brasil (19902007). 208 f. Tese (Doutorado em Educação) - Programa de Pós-Graduação em Educação, Universidade Federal de Santa Catarina, Florianópolis, 2008. 